\title{
An immunohistochemical study of the pancreatic endocrine cells of the ddN mouse
}

\author{
Hyeung Sik Lee ${ }^{1}$, Jeong Hyun Chang ${ }^{1}$, Sae Kwang Ku${ }^{2}$ \\ ${ }^{1}$ Department of Clinical Laboratory Science, College of Health and Therapy, Daegu Haany University, \\ Gyeongsan, Republic of Korea \\ ${ }^{2}$ Department of Anatomy and Histology, College of Oriental Medicine, Daegu Haany University, \\ Gyeongsan, Republic of Korea.
}

\begin{abstract}
The regional distribution and frequency of the pancreatic endocrine cells in the ddN mouse were studied using specific antisera against insulin, glucagon, somatostatin and human pancreatic polypeptide (hPP). In the pancreatic islets, most of insulin-immunoreactive (IR) cells were located in the central region, and glucagon-, somatostatin and hPP-IR cells were located in the peripheral region regardless of the lobe. In the splenic part, glucagon-IR cells were also located in the central regions, and more numerous somatostatin-IR cells were detected in the central regions as compared with the duodenal part. hPP-IR cells were restricted to the peripheral regions in both lobes but more numerous cells were detected in the duodenal portion. In the exocrine parenchyma of the splenic lobe, only insulin- and glucagon-IR cells were detected but all four kinds of IR cells were observed in the duodenal portion. In addition, insulin and hPP-IR cells were also demonstrated in the pancreatic duct regions. In conclusion, some strain-dependent characteristic distributional patterns of pancreatic endocrine cells were found in the $\mathrm{ddN}$ mouse with somewhat different distributional patterns between the two pancreatic lobes.
\end{abstract}

Key words: ddN mouse; pancreas; endocrine cells; immunohistochemistry

\section{Introduction}

ddN mouse is an inbred albino mouse in Japan at 1972, and maintained by Institute for Animal Reproduction (Ibaraki, Japan). ddN mice were found to be more resistant than other strains of mice to inhalation anesthesia using enflurane or isoflurane [1] and it also reported that ddN mice had a higher incidence of opisthotonus than other stains of mice during to inhalation anesthesia [2]. These differences are likely to reflect distinctive characteristics of the central nervous system [3]. Now one of the most widely used inbred mouse strains in anesthesiological fields [4-6] and neurological fields $[7,8]$. It is generally known that the pancreas of vertebrates is subdivided into two regions, one is the exocrine region where digestive enzymes are released and the other is the endocrine region where

Correspondence: Sae-Kwang Ku, Dept. of Anatomy and Histology, College of Oriental Medicine, Daegu Haany University, 290, Yugok-dong, Gyeongsan-si, Gyeongsangbuk-do, 712-715, Republic of Korea; tel.: (+8253) 8191549, fax.: (+8253) 8191269, e-mail: gucci200@hanmail.net regulatory hormones such as insulin, glucagon, somatostatin and pancreatic polypeptide (PP) are released into the blood [9]. Anatomically, the mouse pancreas has two lobes - the splenic and duodenal lobes [10]. The pancreas is a valuable organ for endocrine studies, with the endocrine pancreas being extensively studied in diabetes [11].

It has been reported that the regional distribution and relative frequency of immunoreactive (IR) endocrine cells in the pancreatic islets are different in different portions of the pancreas even within the same pancreas of the same animal $[9,12]$, and a species-dependent characteristic distribution of pancreatic endocrine cells originating from feeding habits has also been suggested [13]. In addition, the strain-dependent characteristic distributions of these IR cells were also detected with the increasing production of genetically mutated laboratory animals and breeding of specific laboratory animals having a specific disease or a unique property, especially in mice $[9,12,14-20]$. The distribution and frequency of pancreatic endocrine cells in the ddN mouse has not yet been forthcoming. Therefore, in the present study, the regional distribution and frequency of the endocrine 
cells in the duodenal and splenic parts of the pancreas of the ddN mouse were studied by immunohistochemistry using specific antisera against insulin, glucagon, somatostatin and human PP (hPP).

\section{Materials and methods}

Animals. Ten specific pathogen free ddN male mice (6-weeks old upon receipt) were acquired from Shizuoka Laboratory Animal Center (Shizuoka, Japan) and used in this study after acclimatization for 2 weeks. After food restriction for about 24 hours, the animals were phlebotomized under ethyl ether anaesthesia. Samples from the splenic and duodenal lobes of pancreas were fixed in Bouin's solution. After paraffin embedding, 3-4 $\mu \mathrm{m}$ serial sections were prepared and stained with hematoxylin and eosin for light microscopic examination of the normal pancreatic architecture.

Immunohistochemistry. Other sections were used for immunostaining using the peroxidase anti-peroxidase (PAP) method [21]. Blocking of nonspecific peroxidase reactions was performed with methanol containing $0.1 \% \mathrm{H}_{2} \mathrm{O}_{2}$, and to avoid non-specific reactions with the background, the sections were incubated with normal goat serum prior to incubation with the specific antibodies (Table 1). The staining procedure reported by $\mathrm{Ku}$ and Lee [9]: after rinsing in phosphate buffered saline (PBS; $0.01 \mathrm{M}, \mathrm{pH}$ 7.4), sections were incubated with secondary antibodies (goat anti-rabbit $\operatorname{IgG}$ or goat antiguinea pig IgG, dilution, 1:200; Sigma, St. Louis MO, USA). Sections were then washed in PBS buffer and finally incubated with PAP complex (dilution, 1:200; Sigma). The peroxidase reaction was carried out using a solution 3,3'-diaminobenzidine tetrahydrochloride containing $0.01 \% \mathrm{H}_{2} \mathrm{O}_{2}$ in Tris- $\mathrm{HCl}$ buffer $(0.05 \mathrm{M}, \mathrm{pH}$ 7.6). After immunostaining, sections were analysed with the use of a light microscope. After immunostaining, the sections were lightly counterstained with Mayer's hematoxylin, and the IR cells were observed under light microscope.

The specificity of each immunohistochemical reaction was determined as recommended by Sternberger [21], including the replacement of specific antiserum by the same antiserum, which
Table 1. Antisera used in this study

\begin{tabular}{|l|c|l|c|}
\hline \multicolumn{1}{|c|}{$\begin{array}{c}\text { Antisera } \\
\text { raised* }\end{array}$} & Code & \multicolumn{1}{|c|}{ Source } & Dilution \\
\hline Insulin & 842613 & $\begin{array}{l}\text { DiaSorin, Stillwater, } \\
\text { MN, USA }\end{array}$ & $1: 2.000$ \\
\hline Glucagon & 927604 & $\begin{array}{l}\text { DiaSorin, Stillwater, } \\
\text { MN, USA }\end{array}$ & $1: 2.000$ \\
\hline Somatostatin & A0566 & $\begin{array}{l}\text { DAKO corp., } \\
\text { Carpenteria, CA, USA }\end{array}$ & $1: 200$ \\
\hline hPP & A619 & $\begin{array}{l}\text { DAKO corp., } \\
\text { Carpenteria, CA, USA }\end{array}$ & $1: 600$ \\
\hline
\end{tabular}

*All antisera were raised in rabbits except for insulin, which were raised in a guinea pig; ${ }^{1} \mathrm{hPP}$ : humane pancreatic polypeptide

had been preincubated with its corresponding antigen - insulin, glucagon, somatostatin and hPP. In addition, to test the cross reactivity of specific antisera with other antisera, immunohistochemical staining was conducted using specific antiserum, which had been preincubated with all other antigens except for its corresponding antigen and the results compared to that of immunohistochemical staining using specific antiserum. No cross reactivities are detected in this study. The frequency of IR cells was calculated as mean \pm standard deviation (S.D.) of 10 parts $(n=10)$ of islets, exocrine and/or duct regions according to that performed in the nude mouse [9]. Among parenchymal cells showing a nucleus, numbers of cells showing immunoreactivities against each antiserum were counted using automated image analysis (DMI, Korea) combined with light microscopy. In the pancreatic islets and duct regions (consisting of duct epithelium and surrounding connective tissues - sub-epithelial connective tissues), numbers of IR cells were counted among 100 cells located in the each region. In addition, the number of each IR cell type was also counted among 1000 parenchymal cells that were located in the exocrine regions, and the percentage of each endocrine cell was also calculated in both the splenic and duodenal lobes.

Table 2. Regional distributions and frequencies of the endocrine cells in the splenic lobe of pancreas of ddN mouse.

\begin{tabular}{|c|c|c|c|c|c|}
\hline \multirow{2}{*}{ IR cells } & \multicolumn{2}{|c|}{ IR cells in the islets* } & \multicolumn{2}{c|}{ IR Cells in the exocrine } & \multirow{2}{*}{ Percentage of each IR cells } \\
\cline { 2 - 5 } & central & peripheral & exocrine** & pancreatic duct* & \\
\hline Insulin & $57.40 \pm 8.18$ & $5.10 \pm 0.99$ & $8.20 \pm 3.46$ & $3.60 \pm 3.53$ & $64.82 \pm 5.29$ \\
\hline Glucagon & $7.40 \pm 4.45$ & $14.60 \pm 4.67$ & $1.56 \pm 0.97$ & $\mathrm{ND}$ & $20.41 \pm 4.79$ \\
\hline Somatostatin & $2.70 \pm 2.45$ & $12.70 \pm 3.06$ & $\mathrm{ND}$ & $\mathrm{ND}$ & $13.45 \pm 4.64$ \\
\hline $\mathrm{hPP}^{1)}$ & $\mathrm{ND}^{2)}$ & $1.50 \pm 0.97$ & $\mathrm{ND}$ & $\mathrm{ND}$ & $1.32 \pm 0.87$ \\
\hline
\end{tabular}

Quantitative frequencies were calculated using automated image analysis process (Soft Image System, Germany) attached to light microscopy; *Cell numbers/100 parenchymal cells; **Cell numbers/1000 parenchymal cells; ${ }^{1} \mathrm{hPP}$ : human pancreatic polypeptide; ${ }^{2} \mathrm{ND}$ : not detected.

Table 3. Regional distributions and frequencies of the endocrine cells in the duodenal lobe of pancreas of ddN mouse.

\begin{tabular}{|c|c|c|c|c|c|}
\hline \multirow{2}{*}{ IR cells } & \multicolumn{2}{|c|}{ IR cells in the islets* } & \multicolumn{2}{|c|}{ IR Cells in the exocrine } & \multirow{2}{*}{ Percentage of each IR cells } \\
\cline { 2 - 5 } & central & peripheral & exocrine** & pancreatic duct* & \\
\hline Insulin & $61.40 \pm 13.15$ & $4.80 \pm 2.25$ & $5.80 \pm 4.21$ & $0.90 \pm 0.88$ & $60.69 \pm 3.14$ \\
\hline Glucagon & $0.90 \pm 0.88$ & $16.60 \pm 3.24$ & $2.20 \pm 1.55$ & ND & $16.51 \pm 2.92$ \\
\hline Somatostatin & $0.70 \pm 0.67$ & $8.70 \pm 2.36$ & $1.80 \pm 1.40$ & ND & $9.32 \pm 1.44$ \\
\hline $\mathrm{hPP}^{1)}$ & $\mathrm{ND}^{2)}$ & $14.30 \pm 5.54$ & $1.30 \pm 0.67$ & $1.00 \pm 1.05$ & $13.48 \pm 3.45$ \\
\hline
\end{tabular}

Quantitative frequencies were calculated using automated image analysis process (Soft Image System, Germany) attached to light microscopy; *Cell numbers/100 parenchymal cells; **Cell numbers/1000 parenchymal cells; ${ }^{1} \mathrm{hPP}$ : human pancreatic polypeptide; ${ }^{2} \mathrm{ND}$ : not detected. 

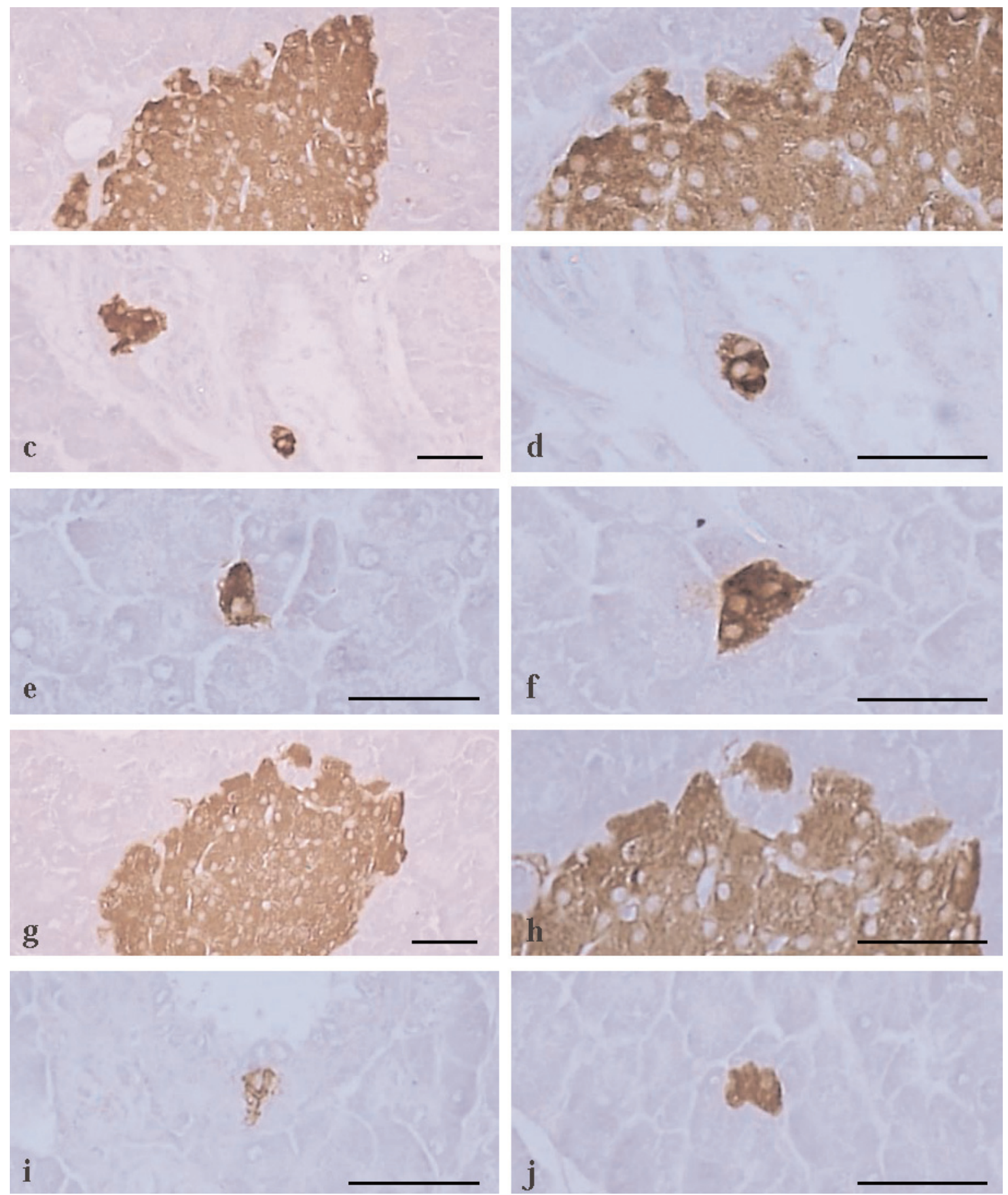

Fig. 1. Insulin-IR cells in the splenic (a-f) and duodenal (g-j) lobes of the pancreas of ddN mice. Most of cells were situated in the central regions of the pancreatic islets $(\mathbf{a}, \mathbf{b}, \mathbf{g}, \mathbf{h})$ and they were located in the sub-epithelial connective tissues of pancreatic duct regions of the splenic lobe as cell clusters $(\mathbf{c}, \mathbf{d})$. Insulin-IR cells were also located in the exocrine region as cell clusters or solitary cells in both the splenic and duodenal lobes $(\mathbf{e}, \mathbf{f}, \mathbf{i}, \mathbf{j})$. Scale bars $=40 \mu \mathrm{m}$; PAP method.

\section{Results}

In this study, all four types of the IR endocrine cells were detected with the antisera against insulin, glucagon, somatostatin and hPP in both lobes of the pancreas of the ddN mice. The pancreatic islets of this study were distinguished as two distinct regions, central and peripheral regions, with their composition of
IR cells. According to the lobe of the pancreas, different regional distributions and frequencies of these IR cells were observed as shown in Tables 2 and 3.

\section{The pancreatic islets region}

In the splenic lobe, most of insulin-IR cells were located in the central region and indeed were the most pre- 

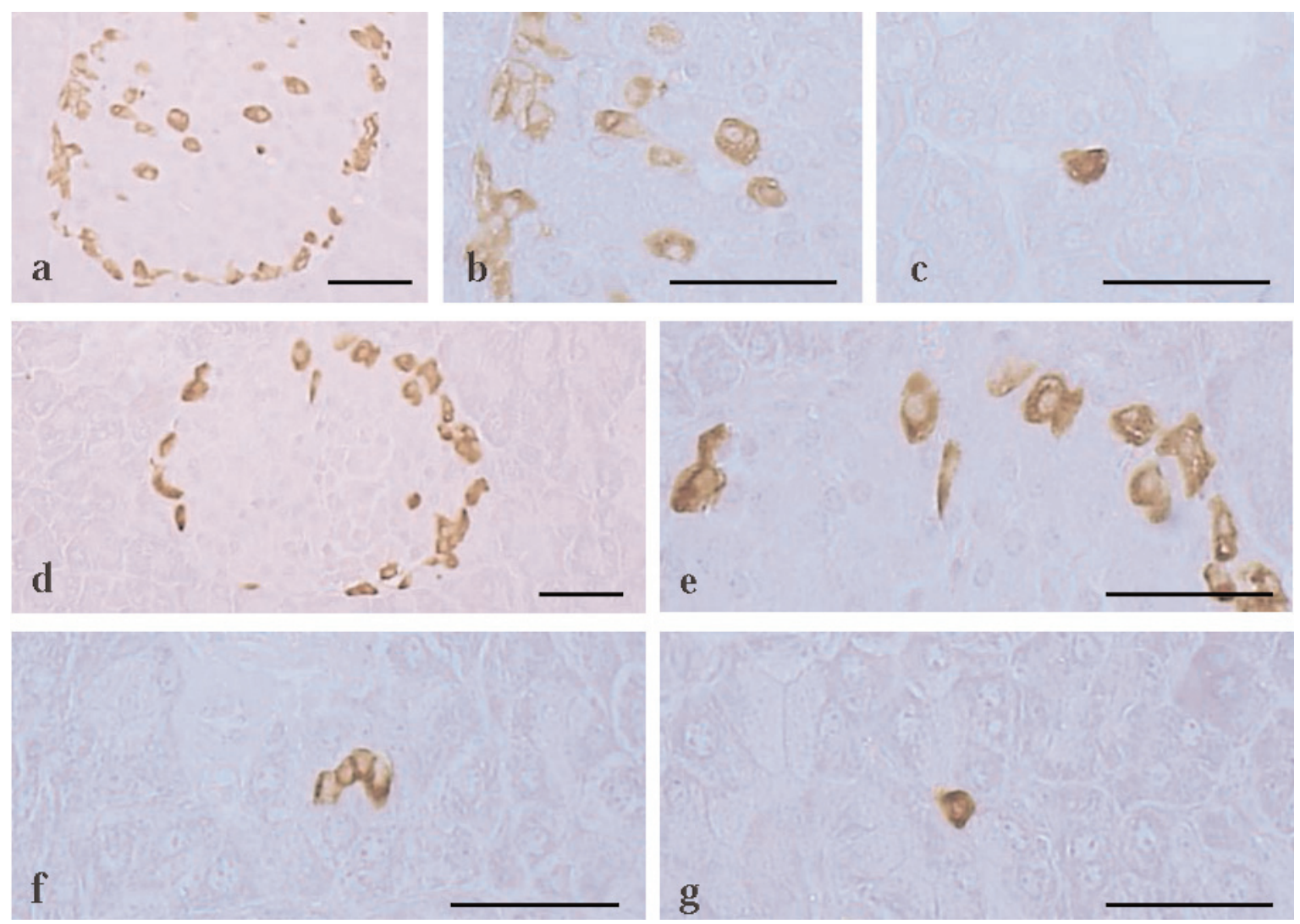

Fig. 2. Glucagon-IR cells in the splenic (a-c) and duodenal (d-g) lobes of the pancreas of ddN mice. Most of the cells were found in the peripheral regions of the pancreatic islets $(\mathbf{a}, \mathbf{b}, \mathbf{d}, \mathbf{e})$. In addition, some cells were also observed in the central regions of the pancreatic islets in the both lobes $(\mathbf{a}, \mathbf{b}, \mathbf{d}, \mathbf{e})$. In the exocrine region of the splenic lobe, they were detected as solitary cells (c). They were distributed in the exocrine region of duodenal lobe as cell clusters (f) or solitary cells $(\mathbf{g})$. Scale bars $=40 \mu \mathrm{m}$; PAP method.
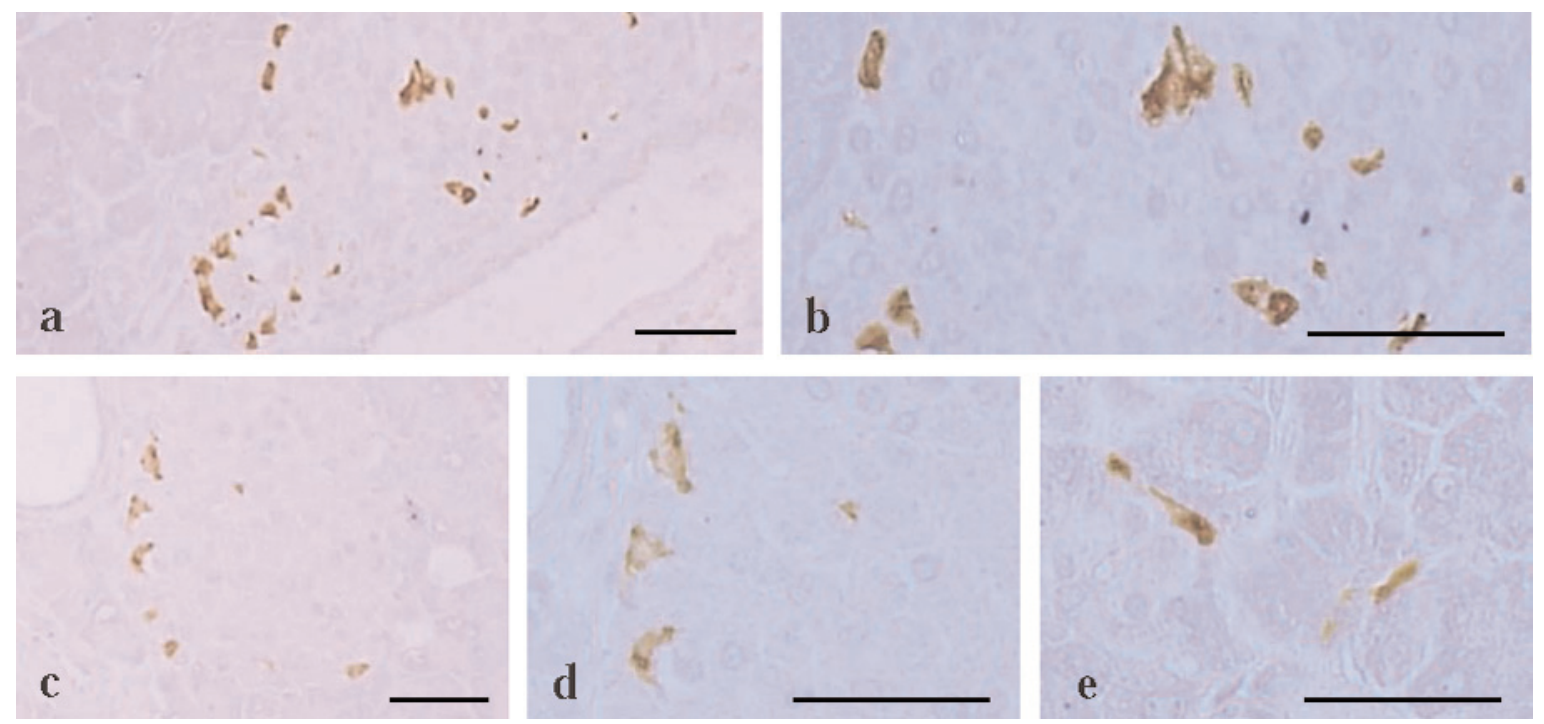

Fig. 3. Somatostatin-IR cells in the splenic (a, b) and duodenal (c-e) lobes of the pancreas of ddN mice. These cells were located in the regions similar to those for glucagon-IR cells in the pancreatic islets in both splenic (a, b) and duodenal lobes (c, d). They were also located in the exocrine as solitary cells in the duodenal lobe (e). Scale bars $=40 \mu \mathrm{m}$; PAP method.

dominant cell type in this region of the pancreatic islets with a frequency of $57.40 \pm 8.18 / 100$ cells. In addition, these cells were also detected in the peripheral regions, but with lower frequency $5.10 \pm 0.99 / 100$ cells (Fig. 1a, b). Glucagon-IR cells were located in the peripheral region of the pancreatic islets and a somewhat lower frequency of cells was noticed in the central region intermingled with insulin-IR cells (Fig. 

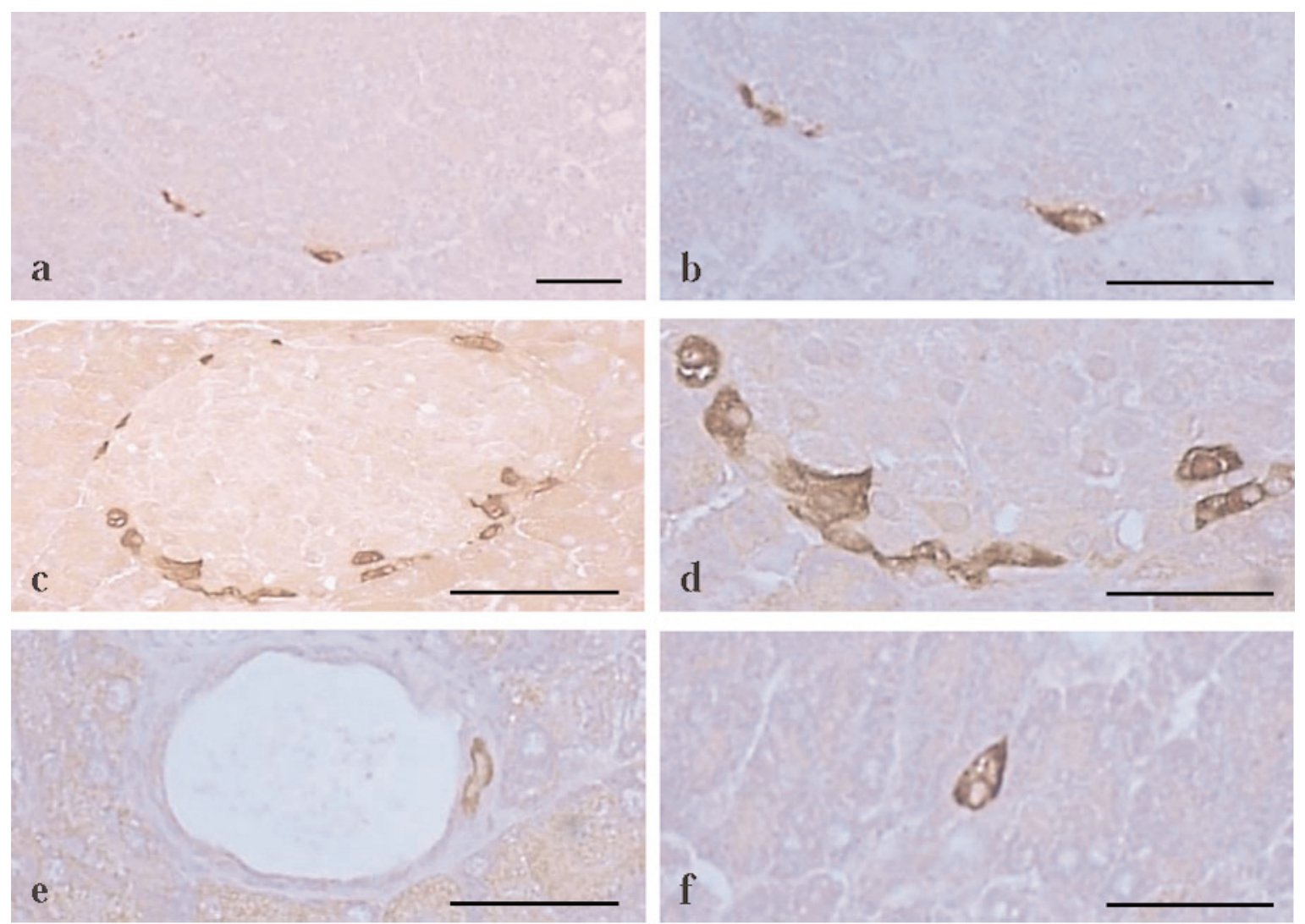

Fig. 4. hPP-IR cells in the splenic (a, b) and duodenal (c-f) lobes of the pancreas of ddN mice. They were restricted to the peripheral regions of the pancreatic islets in both splenic $(\mathbf{a}, \mathbf{b})$ and duodenal lobes $(\mathbf{c}, \mathbf{d})$. They were also located in the sub-epithelial connective tissues of pancreatic duct regions of the splenic lobe (e) and in the exocrine (f) as solitary cells in the duodenal lobe. Scale bars $=40 \mu \mathrm{m}$; PAP method.

$2 \mathrm{a}, \mathrm{b})$. These showed a frequency of $7.40 \pm 4.45$ and $14.60 \pm 4.67 / 100$ cells in the central and peripheral regions, respectively. Somatostatin-IR cells showed distributional patterns similar to those of glucagon-IR cells with $2.70 \pm 2.45$ and $12.70 \pm 3.06 / 100$ cells frequencies in the central and peripheral regions, respectively (Fig. 3a, b). Relatively low numbers of hPP-IR cells were found, and these were restricted to the peripheral regions of pancreatic islets with $1.50 \pm 0.97 / 100$ cells frequency (Fig. 4a, b).

In the duodenal lobe, similar to that of the splenic lobe, most of the insulin-IR cells were located in the central region with $61.40 \pm 13.15 / 100$ cells frequency; they were also detected in the peripheral regions with $4.80 \pm 2.25 / 100$ cells frequency (Fig. 1g, h). GlucagonIR cells were located in the peripheral regions of pancreatic islets, while a few cells were detected in the central regions (Fig. 2d, e). These cells showed $0.90 \pm 0.88$ and $16.60 \pm 3.24 / 100$ cells frequencies in the central and peripheral regions, respectively. Somatostatin-IR cells showed a quite similar distributional pattern in the splenic portion (Fig. 3c, d) with frequencies of $0.70 \pm 0.67$ and $8.70 \pm 2.36 / 100$ cells in the central and peripheral regions, respectively. Relatively higher numbers of hPP-IR cells compared to that of the splenic lobe were found and again were restricted to the peripheral regions of pancreatic islets (Fig. 4c, d) with $14.30 \pm 5.54 / 100$ cells frequency.

\section{The exocrine region}

In the splenic lobe, insulin- and glucagon-IR cells were demonstrated with $8.20 \pm 3.46$ and $1.50 \pm 0.97$ $/ 1000$ cells frequencies, respectively. The insulin-IR cells were detected as cell clusters consisting of 3-4 cells (Fig. 1e) or solitary (Fig. 1f) among acinar cells. Solitary glucagon-IR cells were dispersed among acinar cells (Fig. 2c).

In the duodenal lobe, all four kinds of insulin-, glucagon-, somatostatin- and hPP-IR cells were demonstrated with $5.80 \pm 4.21,2.20 \pm 1.55,1.80 \pm 1.40$ and $1.30 \pm 0.67 / 1000$ cells frequencies, respectively. Insulin-IR cells were detected as cell clusters consisting of 3-5 cellsamong acinar cells (Fig. 1j). In addition, somatostatin- (Fig. 3e) and hPP- (Fig. 4f) IR cells were detected as solitary cells.

\section{The pancreatic duct region}

Only insulin-IR cells were detected in this region of the splenic lobe with $3.60 \pm 3.53 / 100$ cells frequency. They were situated in the sub-epithelial connective tis- 
sues of some pancreatic ducts as cell clusters consisting of 3-7 cells (Fig. 1c, d). In duodenal lobe, insulinand glucagon-IR cells were observed in the subepithelial connective tissues of some pancreatic ducts as cell clusters in insulin-IR cells (Fig. 1i) or as solitary cells in hPP-IR cells (Fig. 4e).

\section{Percentages of the IR cells}

In the splenic lobe, insulin-, glucagon-, somatostatinand hPP-IR cells occupied approximately $64.82 \pm 5.29$, $20.41 \pm 4.79,13.45 \pm 4.64$ and $1.32 \pm 0.87 \%$ of the total IR cell population, respectively (Table 2 ). The insulinIR cell is clearly the most abundant cell type in the splenic lobe of the pancreas of the ddN mouse. In the duodenal lobe, insulin-, glucagon-, somatostatin- and hPP-IR cells occupied approximately $60.69 \pm 3.14$, $16.51 \pm 2.92,9.32 \pm 1.44$ and $13.48 \pm 3.45 \%$ of total IR cell population, respectively (Table 3 ). Again, the insulin-IR cell is the most abundant cell type, as in the splenic lobe, but differently from that of the splenic lobe, more abundant hPP-IR cells were observed as compared with somatostatin-IR cells in the duodenal portion of the pancreas.

\section{Discussion}

Because the function of hormones released from pancreatic endocrine cells is directly related to the regulation of pancreatic digestive enzymes and serum glucose levels [10], most of the endocrine cells in the GEP system originate from the endoderm. Therefore, it cannot be excluded that the differences have genetic or phylogenetic backgrounds. In this study, the regional distribution and relative frequency of the pancreatic endocrine cells were determined in the splenic and duodenal lobes of ddN mouse.

The regional distribution and relative frequency of the pancreatic endocrine cells have been reported in various mouse strains [9,12,14-20]. From these reports, it is well recognized that insulin-IR cells are situated in the central regions of pancreatic islets, and other cells, such as glucagon-, somatostatin- and PPIR cells, surround them. They have also been demonstrated to be associated with acinar cells and pancreatic duct. In the present study, similar to that found in other mouse strains $[9,12,14-20]$, we found that most of the insulin-IR cells were situated in the central regions of the pancreatic islets, and similar distributional patterns of insulin-IR cells were observed in the splenic and duodenal lobes of the ddN mouse.

Although most of the glucagon-IR cells were situated in the peripheral regions of the pancreatic islets, they were also demonstrated in the central regions in the both splenic and duodenal lobes in the present study. Such distributional patterns were also demon- strated in some mouse strains $[9,17,19,20]$. It was also reported that under specific disease conditions, such as obese and diabetic mice, in contrast to normal nonobese littermates, glucagon-IR cells were intermingled with insulin-IR cells in the central regions of pancreatic islets [14].

Generally, somatostatin inhibits the secretion of other hormones and gastric acid and the absorption of amino acids, glucose and fatty acids [22].The specific function of PP is not clear; however, inhibition of food intake has been postulated [10]. The general distribution and frequency of somatostatin- and hPP-IR cells in the pancreas of the ddN mouse was found to be similar to that of other mouse strains $[9,12,14-20]$.

In the present study, somewhat different regional distribution and frequency of pancreatic endocrine cells were detected between the splenic and duodenal lobes. In the splenic portion, somatostatin-IR cells were more numerous than hPP-IR cells in all regions; but in the duodenal portion, hPP-IR cells outnumbered the somatostatin-IR cells in all regions. These differences were considered as strain-dependent characteristics of the ddN mouse and it was also considered that these findings are directly related to the digestive function of $\mathrm{hPP}$ [10]; the duodenal lobes are more tightly contact to the duodenum, therefore, this lobe may be more directly related to the digestive functions, and these variations are also observed in those of nude mouse [9].

In conclusion, some strain-dependent characteristic distributional patterns of pancreatic endocrine cells were found in the ddN mouse. In addition, somewhat different distributional patterns were demonstrated in the two pancreatic lobes.

\section{References}

[ 1] Ogli K, Tsukamoto I, Yokono S, Nogaya J. Anaesthetic mechanism-from molecular to biological aspects. Ann Acad Med Singapore. 1994;23:536-545.

[2] Komatsu H, Oglim K. Opisthotonus during exposure to isoflurane, enflurane, and halothane in mice. Anesthesiology. 1987;67:771-774.

[ 3] Komatsu H, Nogaya J, Anabuki D, Ogli K. The N-methyl-Daspartate (NMDA) receptor antagonist dizocilpine (MK-801) suppresses enflurane-induced opisthotonus in mice. $J$ Anesth. 1993; 7:520-523.

[4] Kuratani N, Komatsu H, Ogli K, Nogaya J, Tanaka T. Multiple but different genetic factors underlie enflurane and isoflurane requirements studied through backcross analysis in C57BL and ddN mice. Anesth Analg. 1996;83:798-803.

[ 5] Hirose T, Inoue M, Uchida M, Shingu K, Inagaki C. Involvement of enhanced glutamate release in halogenated volatile anesthetic-induced excitation in mouse brain. Masui. 1997; 46:3383-3343.

[6] Nakao H, Ono J, Nogaya J, Yokono S, Yube K. The relationship of brain catecholamine levels to enflurane requirements among three strains of mice with different anesthetic sensitivities. J Anesth. 2001;15:88-92.

[7] Yamada K, Satoh M, Tokoi J, Tsuboi M, Nagasaka T. Strain differences of mice in learning of swimming behavior and 
effect of hemicholinium and vasopressin. Observation by a simple water maze apparatus. Yakugaku Zasshi. 1992;112: 824-831.

[ 8] Nakamura T, Miyamoto O, Yamashita S, Keep RF, Itano T, Nagao S. Delayed precursor cell marker response in hippocampus following cold injury-induced brain edema. Acta Neurochir Suppl. 2006;96:134-138.

[9] Ku SK, Lee HS. An immunohistochemical study of the pancreatic endocrine cells of the nude mouse, Balb/c-nu/nu. Eur $J$ Histochem. 2006;50:61-68.

[10] Hsu WH, Crump MH. The endocrine pancreas. In: McDonald LE, Pineda MH, ed. Veterinary endocrinology and reproduction. Lea \& Febiger: Philadelphia; 1989:186-201.

[11] Jansson L, Sandler S. The influence of cyclosporin A on the vascular permeability of the pancreatic islets and on diabetes induced by multiple low dose of streptozotocin in the mouse. Virchows Archiv A Pathol Anat Histopathol. 1988;412:225230.

[12] Yukawa M, Takeuchi T, Watanabe T, Kitamura S. Proportions of various endocrine cells in the pancreatic islets of wood mice (Apodemus speciosus). Anat Histol Embryol. 1999;28: 13-16.

[13] Wieczorek G, Pospischil A, Perentes EA. Comparative immunohistochemical study of pancreatic islets in laboratory animals (rats, dogs, minipigs, nonhuman primates). Exp Toxicol Pathol. 1998;50:151-172.

[14] Starich GH, Zafirova M, Jabelenska R, Petkov P, Lardinois CK. A morphological and immunohistochemical investigation of endocrine pancreas from obese ob+/ob+ mice. Acta Histochem. 1991;90:93-101.
[15] Warbritton A, Gill AM, Yen TT, Bucci T, Wolff GL. Pancreatic islet cells in preobese yellow Avy/- mice: relation to adult hyperinsulinemia and obesity. Proc Soc Exp Biol Med. 1994; 206:145-151.

[16] Gomez-Dumm CL, Console GM, Lunna GC, Dardenne M, Goya RG. Quantitative immunohistochemical changes in the endocrine pancreas of nonobese diabetic (NOD) mice. Pancreas. 1995;11:396-401.

[17] $\mathrm{Ku} \mathrm{SK}$, Lee HS, Lee JH. An immunohistochemical study of pancreatic endocrine cells in SKH-1 hairless mice. Eur J Histochem. 2002;46:229-236.

[18] Ku SK, Lee HS, Lee JH. An immunohistochemical study on the pancreatic endocrine cells of the C57BL/6 mouse. $J$ Vet Sci. 2002;3:327-333.

[19] $\mathrm{Ku}$ SK, Lee HS, Lee JH. Immunohistochemical study of the pancreatic endocrine cells in the Balb/c mice: An unique distributional pattern of glucagon. J Vet Sci. 2002;3:167-173.

[20] Ku SK, Lee HS. Distribution and frequency of endocrine cells in the pancreas of the ddY mouse: an immunohistochemical study. Eur J Histochem. 2005;49:125-130.

[21] Sternberger LA. The unlabeled antibody peroxidase-antiperoxidase (PAP) method. In: Sternberger LA, ed. Immunocytochemistry. John Wiley \& Sons: New York; 1979:104-169.

[22] Brazeau P, Vale W, Burgurs R, et al. Hypothalamic polypeptide that inhibits the secretion of immunoreactive pituitary growth hormone. Science. 1973;179:77-79.

Submitted: 22 February, 2010 Accepted after reviews: 6 April, 2010 